\title{
Seatbelt use by pregnant women: a survey of knowledge and practice in Hong Kong
}

\author{
WC Lam *, William WK To, Edmond SK Ma
}

\section{A B S T R A C T}

Introduction: The use of motor vehicles is common during pregnancy. Correct seatbelt use during pregnancy has been shown to protect both the pregnant woman and her fetus. This survey aimed to evaluate the practices, beliefs, and knowledge of Hong Kong pregnant women of correct seatbelt use, and identify factors leading to reduced compliance and inadequate knowledge.

Methods: A self-administered survey was completed by postpartum women in the postnatal ward at the United Christian Hospital, Hong Kong, from January to April 2015. Eligible surveys were available from 495 women. The primary outcome was the proportion of pregnant women who maintained or reduced seatbelt use during pregnancy. Secondary outcomes were analysed and included knowledge of correct seatbelt use, as well as contributing factors to non-compliance and inadequate knowledge.

This article was published on 19 Aug 2016 at www.hkmj.org.
Results: There was decreased compliance with seatbelt use during pregnancy and the decrease was in line with increasing gestation. Pregnant women's knowledge about seatbelt use was inadequate and only a minority had received relevant information. Women who held a driving licence and had a higher education level were more likely to wear a seatbelt before and during pregnancy. Women with tertiary education or above knew more about seatbelt use.

Conclusions: Public health education for pregnant women in Hong Kong about road safety is advisable, and targeting the lower-compliant groups may be more effective and successful.
Hong Kong Med J 2016;22:420-7
DOI: $10.12809 / \mathrm{hkmj} 164853$

\begin{abstract}
${ }^{1}$ WC Lam *, MPH (CUHK), FHKAM (Obstetrics and Gynaecology)
${ }^{1}$ WWK To, MD, FHKAM (Obstetrics and Gynaecology)

${ }^{2}$ ESK Ma, MD, FHKAM (Community Medicine)
\end{abstract}
1 Department of Obstetrics and Gynaecology, United Christian Hospital, Kwun Tong, Hong Kong
The Jockey Club School of Public Health and Primary Care, The Chinese University of Hong Kong, Shatin, Hong Kong
* Corresponding author: lamwc2@ha.org.hk

New knowledge added by this study

- There was decreased compliance with seatbelt use by pregnant women in Hong Kong. The decrease in compliance became more pronounced as gestation increased. This may be related to lack of relevant information and misconceptions.

Implications for clinical practice or policy

- As a form of public health and road traffic safety promotion, information about seatbelt use during pregnancy should be provided to pregnant women, health care workers, and all road traffic users.

\section{Introduction}

Road traffic safety is an important public health issue. Health care professionals are usually involved in the treatment of road traffic accident victims rather than prevention of their occurrence or minimising the severity of injury. Education about and promotion of road traffic safety is important for all; pregnant women are no exception. Safety issues relate to both the mother and her fetus, and different information and/or a different approach may be required. With any kind of intervention during pregnancy, an emphasis on the safety of the fetus may improve compliance.

The number of pregnant drivers in Hong Kong is unknown, but the use of motor vehicles including private car, taxi, and public light bus is common during pregnancy. To promote maternal seatbelt use among the local pregnant population, information about their beliefs is essential.

Correct seatbelt use during pregnancy has been shown to protect both the pregnant woman and her fetus. There is evidence that pregnant women who do not wear a seatbelt and who are involved in a motor vehicle accident are more likely to experience excessive bleeding and fetal death. ${ }^{1-3}$ Compliance and proper use of the seatbelt are crucial. Incorrect placement of the seatbelt and a subsequent accident may result in fetal death due to abruptio placentae. ${ }^{4}$ The three-point restraint (ie shoulder harness in addition to a lap belt) provides more protection for the fetus than a lap belt alone. Previous studies have revealed incorrect positioning of the seatbelt 
in $40 \%$ to $50 \%$ of pregnant women. ${ }^{5,6}$ Various other studies have shown reduced seatbelt compliance during pregnancy. ${ }^{7}$ The proportion of seatbelt use has been reported to be around $70 \%$ to $80 \%$ before pregnancy, but reduced by half at 20 weeks or more of gestation., There is also evidence that pregnant women lack information about the proper use of a seatbelt and its role in preventing injury: only $14 \%$ to $37 \%$ of pregnant women received advice from health care professionals..$^{5-8}$ The common reasons for not using a seatbelt have been reported to include discomfort, inconvenience, forgetfulness, and fear of harming the fetus. ${ }^{9}$

In this study, the current practice and knowledge of Hong Kong pregnant women about seatbelt use was surveyed, and any determining factors were identified. The results will enable public health education and promotion to be targeted to at-risk groups to improve road traffic safety among local pregnant women.

\section{Methods}

\section{Study design}

This was a cross-sectional survey using a convenient sampling carried out from January to April 2015. A self-administered questionnaire was distributed to postpartum women in the postnatal ward of United Christian Hospital (UCH) in Hong Kong. Participation in the survey was entirely voluntary.

Questionnaires were analysed if at least $50 \%$ of questions were answered, including the main outcomes. Those from women who did not understand the content or who did not understand Chinese or English were excluded.

\section{Questionnaire}

The questionnaire was based on a pilot study, with questions revised after review. It was available in English and Chinese (traditional and simplified) versions and was divided into four parts. The first part included demographic and pregnancy information and driving experience. The second part focused on practice of seatbelt use before and during pregnancy, any change in habit with progression of pregnancy, and the reason(s) for non-use of a seatbelt. The third part related to awareness and knowledge of the Road Traffic Ordinance on seatbelt use and the correct use of both lap and shoulder belts. Text descriptions and diagrams of different restraint positions were provided. The correct way is to place the lap belt below the abdomen and the shoulder belt diagonally across the chest. The diagram of restraint positions were adopted from the leaflet "Protect your unborn child in a car" by the Transport Department of Hong Kong with permission. ${ }^{10}$ The final part asked whether the postpartum woman had received any advice about seatbelt use during pregnancy, the

\section{香港孕婦對於使用安全帶的知識和實踐的 問卷調查 \\ 林慧翔、杜榮基、馬紹強}

引言：懷孕期間乘搭汽車或駕車很常見, 而正確使用安全帶可保護孕 婦和胎兒。本研究旨在評估香港孕婦對於使用車輛安全帶的觀念和實 踐、正確使用安全帶的知識, 以及導致知識不足和不佩戴安全帶的理 由。

方法：2015年1月至4月期間，研究人員邀請香港基督教聯合醫院產後 病房住院的產婦填寫問卷調查, 共495名婦女完成問卷。主要搜集的 資料包括有關懷孕期間維持使用和減少使用安全帶的比例; 其次包括 正確使用安全帶的知識, 以及導致知識不足和不佩戴安全帶的理由, 並進行分析。

結果：懷孕期間安全帶的使用率下降, 且與妊娠期增長相關。孕婦對 於使用車輛安全帶的知識貧乏, 只有少數曾經接收相關資料。持有駕 駛執照和有較高教育水平的孕婦在懷乃前和懷孕期間有較高機會佩戴 安全帶。擁有大專或以上教育程度的婦女對正確使用安全帶有較多認 識。

結論：建議為香港孕婦提供有關道路安全的公共健康教育, 尤其是要 加強向不佩戴安全帶的孕婦宣傳, 道路安全教育才能更有效和成功。

source of information, and whether they thought such information was useful and/or relevant.

\section{Statistical analysis}

\section{Sample size calculation}

Using the results of overseas studies as reference, the sample size was calculated according to the assumption that around $80 \%$ of Hong Kong pregnant women use a seatbelt. A previous questionnaire survey among postpartum women at a local hospital indicated that a response rate of approximately $80 \%$ could be expected. ${ }^{11}$ We assumed the margin of error that could be accepted to be $4 \%$, with a confidence level of 95\%, and using this formula: $n=z^{2} \times p x$ $(1-p) / d^{2}$ (where $p=$ proportion of wearing seatbelt [0.8]; $d=$ margin of error [0.04]; and $z$ value $=1.96$ ), the adjusted sample size was 481 .

All statistical analysis was performed using PASW Statistics 18 (Release Version 18.0.0; SPSS Inc, Chicago [IL], US). For categorical data, the Chi squared test was used to compare knowledge about seatbelt use in wearers and non-wearers. For continuous data with a highly skewed distribution, non-parametric test (Mann-Whitney $U$ test for two groups and Kruskal-Wallis $\mathrm{H}$ test for more than two groups) was used to compare the knowledge of correct seatbelt use. Knowledge score was calculated based on the answer to questions about the Road Traffic Ordinance on seatbelt use and the proper way to use both the lap and shoulder belts. One point was given for each correct answer. The critical level of 
statistical significance was set at 0.05 .

The relative effects of factors (age, marital status, education level, resident status, husband's occupation, family monthly income, respondent's and husband's driving license holder status, frequency of public transport use, and stage of pregnancy) that might influence seatbelt use during pregnancy were estimated using generalised estimating equation (GEE). The outcome variables were dichotomous correlated responses (eg use of seatbelt in different gestations), and the outcome variables were assumed to be independent. The issue about statistical significance due to lack of independence was corrected using GEE.

To account for the interdependence of observations, we used robust estimates of variance (GEE) by including each period of observation as a cluster. For use of a seatbelt before and during each trimester of pregnancy, since the responses were correlated as time progressed, the GEE model with working correlation matrix was adopted. ${ }^{12}$

\section{Results}

\section{Demographic data}

There were 769 postpartum women in the postnatal ward during the study period. A total of 550 questionnaires were distributed by convenience and the response rate was $91 \%$ with 501 questionnaires returned. The remaining women $(n=49,9 \%)$ either refused to participate or did not return the questionnaire. Among the returned questionnaires, six were excluded due to missing information on the main outcomes of the survey or they were $<50 \%$ complete. At the end of the recruitment period, 495 (90\%) questionnaires were valid for analysis.

The majority (93.5\%) of respondents were aged between 21 and 40 years. Only 10 (2\%) were English speakers; others (98\%) spoke Cantonese or Mandarin as their first language and completed the Chinese questionnaire. With regard to education level, 188 (38\%) women had received tertiary education or above, 290 (58.6\%) secondary education, and $14(2.8 \%)$ primary education. There was no existing information about any association between pregnant woman or spousal occupation and compliance with or knowledge about seatbelt use. We therefore investigated whether occupation was a relevant factor, for example, driver and health care worker. Around half $(n=216,43.6 \%)$ of the women were housewives, 57 (11.6\%) were professionals, and $14(2.8 \%)$ were medical health care workers. Among spouses, $32(6.5 \%)$ were drivers, two (0.4\%) were medical health care workers, and 122 (24.6\%) were professionals. Other occupations were unrelated to transportation or health care, including clerk, construction site worker, restaurant waiter, and chef. Overall, 439 (88.7\%) women were Hong Kong residents, others were new immigrants or double- entry permit holders from Mainland China. Of the respondents, 477 (96.4\%) women had attended regular antenatal check-ups, and 215 (43.4\%) were first-time mothers.

\section{Driving experience and mode of transport}

Around half of the spouses (49.1\%) but only 71 (14.3\%) women held a Hong Kong driving licence. Among those women with a driving licence, only $16(22.5 \%)$ drove daily, and seven (9.9\%) only at weekends. Public transport was used daily by 300 (60.6\%) women. Among different means of public transport, buses $(53.7 \%)$ were the most commonly used but not all seats on buses have seatbelts. In public light buses and taxis, use of a seatbelt, if available, is mandatory: $38.6 \%$ and $15.2 \%$ of respondents used public light buses and taxis, respectively.

\section{Use of a seatbelt before and during pregnancy}

Of the respondents, 379 (76.6\%) pregnant women reported using a seatbelt in the 6 months before pregnancy, but compliance was reduced as pregnancy progressed. Seatbelt use was reduced to $73.5 \%$ in the first trimester, $70.5 \%$ in the second trimester, and $67.1 \%$ in the third trimester (Table 1). There were 26 women who changed their behaviour from not wearing a seatbelt prior to pregnancy to wearing one after they became pregnant. Therefore the total number of ever seatbelt users was 405. Analysis of the knowledge score was performed by excluding these 26 women; the result showed a similar finding and statistical significance.

\section{Reasons for not using a seatbelt during pregnancy}

With regard to the reasons for not using a seatbelt

TABLE I. Use of seatbelt before and during pregnancy

\begin{tabular}{lc}
\hline Seatbelt use & No. (\%) of women $(\mathbf{n}=\mathbf{4 9 5})$ \\
\hline $\begin{array}{l}\text { Before pregnancy } \\
\text { Yes }\end{array}$ & $379(76.6)$ \\
No & $116(23.4)$ \\
During 1st trimester & \\
Yes & $364(73.5)$ \\
No & $131(26.5)$ \\
During 2nd trimester & $349(70.5)$ \\
Yes & $146(29.5)$ \\
No & \\
During 3rd trimester & $332(67.1)$ \\
Yes & $163(32.9)$ \\
\hline No &
\end{tabular}


at any time during pregnancy, 156 (89.1\%) of 175 women stated that the seatbelt caused discomfort, $22(12.6 \%)$ thought seatbelts were not useful, and 79 (45.1\%) worried that they would cause harm to the fetus (Table 2). Apart from the three stated options in the questionnaire, several respondents stated that the travelling distance was usually short on public light buses and the time taken to buckle up and unfasten the seatbelt may delay other passengers. Other women admitted to being lazy or forgetful, or were just not in the habit of using a seatbelt. They also found seatbelts inconvenient because those on public transport were "not user-friendly", "too short", or were "dirty" (Table 2).

\section{Knowledge of seatbelt use during pregnancy}

Of the respondents, 216 (43.6\%) correctly answered that pregnant women are not exempted from seatbelt use according to the Road Traffic Ordinance. The remaining $56.4 \%$ either answered wrongly or did not know the answer. Approximately $52.7 \%$ women correctly pointed out that appropriate use of a seatbelt will not harm the fetus. Although around half of the women wrongly believed that pregnant women are exempted from seatbelt legislation or that use of a seatbelt will harm the fetus, 358 (72.3\%) stated that pregnant women should wear a seatbelt. When the three-point seatbelts were shown on the diagrams, $403(81.4 \%)$ women could identify the correct way of wearing the seatbelt with the lap strap placed below the bump, not over it (Table 3).

Among all the respondents, 90 (18.2\%) women never wore a seatbelt, and the other 405 (81.8\%) were seatbelt users either before or during pregnancy. Comparison of responses revealed that never wearers of a seatbelt had significantly poorer knowledge in three of the four questions about seatbelt use during pregnancy $(\mathrm{P}<0.05)$ [Table 3].

\section{Information about seatbelt use during pregnancy}

Information about seatbelt use had been received by only 32 (6.5\%) women. Among them, 13 (40.6\%) had derived the information from the internet, others from

TABLE 2. Reasons for not using a seatbelt

\begin{tabular}{lr}
\hline Reason & No. (\%) of women (n=175) \\
\hline Wearing seatbelts is not useful & $22(12.6)$ \\
Wearing seatbelts causes discomfort & $156(89.1)$ \\
Wearing seatbelts may harm the fetus & $79(45.1)$ \\
Not available on bus/minibus/MTR & $22(12.6)$ \\
Forgot, lazy, no habit to use seatbelts & $9(5.1)$ \\
\hline Inconvenient; seatbelts on public transport are short and dirty/not user-friendly & $8(4.6)$ \\
\hline Travel only short distance by minibus & $9(5.1)$ \\
\hline
\end{tabular}

Abbreviation: MTR = Mass Transit Railway

TABLE 3. Knowledge of seatbelt use (seatbelt users vs non-users)

\begin{tabular}{|c|c|c|c|c|}
\hline & \multicolumn{3}{|c|}{ No. (\%) of women } & \multirow[t]{2}{*}{$P$ value } \\
\hline & $\begin{array}{l}\text { Respondents } \\
(n=495)\end{array}$ & $\begin{array}{c}\text { Never use } \\
\text { seatbelt }(n=90)\end{array}$ & $\begin{array}{l}\text { Ever use seatbelt } \\
\qquad(n=405)\end{array}$ & \\
\hline Pregnant women are exempted from seatbelt legislation or not? & & & & 0.016 \\
\hline Correct answer & $216(43.6)$ & $29(32.2)$ & $187(46.2)$ & \\
\hline Wrong answer / do not know & $279(56.4)$ & $61(67.8)$ & $218(53.8)$ & \\
\hline Will the use of a seatbelt cause harm to the fetus? & & & & 0.082 \\
\hline Correct answer & $261(52.7)$ & $40(44.4)$ & $221(54.6)$ & \\
\hline Wrong answer / do not know & $234(47.3)$ & $50(55.6)$ & $184(45.4)$ & \\
\hline Pregnant women should wear seatbelts or not? & & & & $<0.001$ \\
\hline Correct answer & $358(72.3)$ & $50(55.6)$ & $308(76)$ & \\
\hline Wrong answer / do not know & $137(27.7)$ & $40(44.4)$ & $97(24)$ & \\
\hline Identify the correct way to position seatbelts during pregnancy & & & & 0.001 \\
\hline Correct answer & $403(81.4)$ & $62(68.9)$ & $341(84.2)$ & \\
\hline Wrong answer & $92(18.6)$ & $28(31.1)$ & $64(15.8)$ & \\
\hline
\end{tabular}


staff of a government and private clinic, magazine, and publications of Transport Department. Seven (21.9\%) received information from friends or family members; one had a car accident during pregnancy and was given relevant information by health care workers at the Accident and Emergency Department. Most ( $n=426,86 \%)$ women expressed the view that information about seatbelt use during pregnancy was useful and necessary.

\section{Factors influencing use of seatbelt during pregnancy}

Among all potential factors, women who held a driving licence (odds ratio $[\mathrm{OR}]=3.28 ; \mathrm{P}=0.004$ ) or had a higher level of education $(\mathrm{OR}=2.13$; $\mathrm{P}<0.001)$ were more likely to use a seatbelt. Considering time as another variable, as pregnancy progressed women were significantly less likely to use a seatbelt $(\mathrm{OR}=0.84 ; \mathrm{P}<0.001)$ [Table 4].

\section{Factors influencing knowledge about correct seatbelt use}

Women with a lower education level $(\mathrm{P}<0.001)$ were less aware of the Road Traffic Ordinance on seatbelt use, the protective effects of a seatbelt during pregnancy, and the correct way to position both the lap and shoulder belts (Table 5).

\section{Discussion}

\section{Main findings}

In this study, $76.6 \%$ of Hong Kong pregnant women were consistent seatbelt wearers before pregnancy; this is similar to overseas studies which reported $70 \%$ to $80 \%{ }^{5,7}$ Compliance was reduced during all trimesters, and decreased as gestation progressed. Only 26 women changed their behaviour from non-users to users after becoming pregnant. It also demonstrated the misconception about the effects of seatbelt use on pregnancy and the fetus. Pregnant women's knowledge about seatbelt use was inadequate and only a minority had received relevant information. Women who held a driving licence or had a higher education level were more likely to wear a seatbelt before and during pregnancy. Women with a tertiary education or above were more knowledgeable about seatbelt use.

\section{Strengths and limitations}

As far as we know, this is the first survey in Hong Kong of the knowledge of pregnant women about seatbelt use and their associated practice, with a reasonably high response rate. One limitation of the study was that the questionnaire was not validated and there were overlapping categories for numerical variables. Results and experience in this study can serve to revise the questions for a future study with improved validity and reliability. During the study period, 769 postpartum women stayed in the postnatal ward and 495 (64\%) completed questionnaires were collected. The proportion included was relatively high, but still the method of convenient sampling may have affected the representativeness of the sampled subjects. Moreover this was a single-centre survey in the obstetric unit of a district hospital. The UCH provides obstetric services to the population in the

TABLE 4. Determining factors influencing use of a seatbelt before and during pregnancy

\begin{tabular}{|c|c|c|}
\hline Potential factors* & Odds ratio ( $95 \%$ confidence interval) & $P$ value \\
\hline Older age & $1.24(0.9-1.71)$ & 0.195 \\
\hline Married status (vs single/divorced) & $1.28(0.61-2.69)$ & 0.52 \\
\hline Tertiary or above education level (vs primary/secondary education) & $2.13(1.43-3.16)$ & $<0.001$ \\
\hline Hong Kong resident (vs new immigrant/double-entry permit) & $1.2(0.68-2.14)$ & 0.528 \\
\hline \multicolumn{3}{|l|}{ Husband's occupation (vs government servant/health care worker) } \\
\hline Professional & $0.41(0.08-1.95)$ & 0.261 \\
\hline Driver & $1.53(0.25-9.38)$ & 0.647 \\
\hline Others & $0.31(0.07-1.4)$ & 0.127 \\
\hline Higher family monthly income & $1.25(0.97-1.62)$ & 0.082 \\
\hline Driving licence holder (vs non-holder) & $3.28(1.46-7.34)$ & 0.004 \\
\hline Husband has driving licence (vs non-holder) & $1.45(0.96-2.19)$ & 0.076 \\
\hline More frequent use of public transportation & $1.04(0.83-0.9)$ & 0.739 \\
\hline Later stage in pregnancy & $0.84(0.78-0.9)$ & $<0.001$ \\
\hline
\end{tabular}

* Age, family monthly income, frequency of public transport use, and stage of pregnancy were analysed as continuous variables: age - from young to older age; family monthly income - from low to high income; frequency of public transport use- from most frequent to least frequent; stage in pregnancy — from pre-pregnancy to 3rd trimester of pregnancy 
TABLE 5. Determining factors influencing knowledge score for correct seatbelt use*

\begin{tabular}{|c|c|c|c|}
\hline Potential factors & No. & $\begin{array}{l}\text { Score for knowledge about seatbelt use } \\
\text { during pregnancy }\end{array}$ & $P$ value \\
\hline Age-group (years) & & & 0.354 \\
\hline$\leq 20$ & 13 & $2(1-3)$ & \\
\hline $21-30$ & 195 & $3(1-4)$ & \\
\hline $31-40$ & 268 & $3(2-4)$ & \\
\hline$>40$ & 19 & $2(2-4)$ & \\
\hline Marital status & & & 0.643 \\
\hline Married & 455 & $3(2-4)$ & \\
\hline Single & 31 & $2(2-3)$ & \\
\hline Divorced & 5 & $2(0.5-3.5)$ & \\
\hline Education level & & & $<0.001$ \\
\hline Primary school & 14 & $1(0-2)$ & \\
\hline Secondary school & 290 & $2(1-3)$ & \\
\hline Tertiary or above & 188 & $3(2-4)$ & \\
\hline Hong Kong residency & & & 0.116 \\
\hline Hong Kong resident & 439 & $3(2-4)$ & \\
\hline Non-Hong Kong resident & 56 & $2(1.25-3)$ & \\
\hline Husband occupation & & & 0.158 \\
\hline Civil servant/health care worker & 18 & $3(2.75-4)$ & \\
\hline Professional & 122 & $3(2-4)$ & \\
\hline Driver & 32 & $3(1-3.75)$ & \\
\hline Others & 323 & $2(1-3)$ & \\
\hline Family monthly income (HK\$) & & & 0.12 \\
\hline$<\$ 10000$ & 49 & $2(1-3)$ & \\
\hline$\$ 10000-20000$ & 153 & $3(1-4)$ & \\
\hline$\$ 20000-30000$ & 126 & $3(1.75-4)$ & \\
\hline$>\$ 30000$ & 159 & $3(2-4)$ & \\
\hline Driving licence holder & & & 0.084 \\
\hline Yes & 71 & $3(2-4)$ & \\
\hline No & 423 & $3(2-4)$ & \\
\hline Driving licence of husband & & & 0.927 \\
\hline Yes & 243 & $3(1-4)$ & \\
\hline No & 242 & $3(2-4)$ & \\
\hline
\end{tabular}

* Data are shown as median (25th-75th percentile) and analysed by Mann-Whitney $U$ test and Kruskal-Wallis H test. Some data are missing as not all participants answered all of the questions

Kowloon East region. The geographical location of a clinic could dictate the mode of travelling to attend antenatal hospital appointments. Although taxis and public light buses are the usual mode of transport, some women may have taken the bus or Mass Transit Railway, and these do not require use of a seatbelt. Furthermore, the delivery rate at $\mathrm{UCH}$ was less than $10 \%$ of the total deliveries in Hong Kong, therefore the results may not be applicable to other clusters with patients of different education levels, driving experience, and transportation habits.

In addition, those who were unable to read or understand Chinese or English were excluded. These were usually illiterate or non-Hong Kong residents, and may be the group with the lowest compliance and poorest knowledge about seatbelt use. There were 49 women who refused to participate and six who did not complete the questionnaire; this $10 \%$ also introduced inaccuracy and bias in our data. Reporting bias is another concern. Discrepancies between observed and self-reported seatbelt use were found in a previous study. ${ }^{13}$ Anonymity of the questionnaires might have minimised reporting bias. Although all demographic variables included in the questionnaire were analysed, there were other potential confounders that might have affected the 
knowledge score and the use of a seatbelt during pregnancy. These were not investigated and hence not adequately adjusted in the knowledge score analysis or in the GEE model, for example prior traffic accidents in the respondents and their family members, risk-taking behaviours such as smoking, alcohol drinking, and drug use. Finally, multivariate instead of univariate analysis of the factors affecting knowledge score could be performed to investigate the relationship among different variables.

\section{Interpretation}

Prevention plays a major role in ensuring maternal and fetal survival in road traffic accidents. Motor vehicle crashes are responsible for severe maternal injury and fetal loss. Despite existing knowledge about the protective effects of wearing a seatbelt, pregnant women remain poorly compliant. This was confirmed in this local survey and in overseas studies. ${ }^{14,15}$

In the Report on Confidential Enquiries into Maternal Deaths in the United Kingdom 1994-1996 published by the Royal College of Obstetricians and Gynaecologists, 13 pregnant women died as a result of road traffic accidents. One of the victims did not use a seatbelt and was forcibly ejected from the vehicle. ${ }^{16}$ Ten years later, in a more recent Report on Confidential Enquiries into Maternal Deaths in the United Kingdom 2006-2008, ${ }^{17}$ there were 17 pregnant women who died as a result of road traffic accidents. A specific recommendation was made in the report: "All women should be advised to wear a 3-point seat belt throughout pregnancy, with the lap strap placed as low as possible beneath the 'bump' lying across the thighs and the diagonal shoulder strap above the 'bump' lying between the breasts. The seat belt should be adjusted to fit as snugly and comfortably as possible, and if necessary the seat should be adjusted". ${ }^{17}$

According to the Road Traffic Ordinance in Hong Kong, drivers and passengers must wear seatbelts where provided. The exceptions are when reversing a vehicle, making a three-point turn, manoeuvring in and out of a parking place, and those who have a medical certificate and have been granted an exemption on medical grounds by the Commissioner for Transport. ${ }^{18}$ According to a report of the Transport Department of Hong Kong, the total number of road traffic accidents was 14 436 in 2003. In 2013, the number rose to 16089 . The number of pregnant women involved or injured in road traffic accidents is unknown. ${ }^{19}$ The Hong Kong SAR Government revises seatbelt legislation regularly to enhance road safety. Since 1 January 2001, passengers have been required to wear a seatbelt, if available, in the rear of taxis as well as in the front. Since 1 August 2004, passengers on public light buses have also been required to wear a seatbelt where one is fitted. ${ }^{20,21}$ Stickers were put inside buses and taxis to remind passengers of their responsibility to wear a seatbelt and to give clear instructions on the correct way to wear it. Nonetheless, the requirement to use a seatbelt and its protective effects were not well recognised among the respondents in this survey. This may be due to the lack of information provision as only $6.5 \%$ of women had received information related to seatbelt use in pregnancy.

In this study, those with a lower education level had poorer knowledge about seatbelt use in pregnancy. Effective public education should target these women. Using diagrams as instruction can be simple and direct so that those with a lower education level or who only use public transportation occasionally can easily understand and follow the advice. In the past, leaflets or stickers about seatbelt use were widely seen, especially after introduction of the new legislation, but those specifically targeted to the pregnant population were not common. Maternal child health centres and antenatal clinics of government hospitals are ideal places to distribute educational material. Television announcements may also convey the message effectively, not only to pregnant women, but to all road traffic users. It is also a good opportunity to inform drivers and other passengers so that they can help pregnant women as well as the elderly and disabled who use public transport. Regular spot-checks on public transport and law enforcement may also encourage compliance with seatbelt use. The majority of doctors and midwives give advice about seatbelt use only if asked. This survey demonstrated that the proportion of pregnant women who received seatbelt information was very small. It is recommended that written instructions and advice should be available from well-informed health care professionals, and pregnant women should always be encouraged to wear a correctly positioned seatbelt. Obstetricians, midwives, and general practitioners play an important role in disseminating information. A study in Ireland showed that $75 \%$ of general practitioners believed women should wear seatbelts in the third trimester, although only $30 \%$ provided regular advice and fewer than $50 \%$ indicated that they were aware of the correct advice to give. ${ }^{22}$

\section{Conclusions}

This study demonstrated decreased compliance with seatbelt use during pregnancy that continued to decrease as pregnancy progressed. Women with a lower education level or without a driving licence were less likely to use a seatbelt during pregnancy. The former were also less aware of the Road Traffic Ordinance on seatbelt use and the correct way to position both the lap and shoulder belts. Only a minority of pregnant women had received information about seatbelt use. Future studies to 
assess the knowledge of Hong Kong health care workers about use of seatbelts in pregnancy may enhance the awareness and involvement of medical professionals in educating pregnant women on this issue. Publicity and education about road safety by health care providers and the government are advised, and targeting the lower compliant groups may be more effective and successful.

\section{Acknowledgements}

The authors gratefully acknowledge $\mathrm{Mr}$ Edward Choi for his valuable statistical advice, the staff in the postnatal ward of $\mathrm{UCH}$ for helping to collect the questionnaires, and the Transport Department of Hong Kong for permission to use the diagram of restraint positions adopted from the leaflet "Protect your unborn child in a car" on the questionnaires.

\section{Declaration}

All authors have disclosed no conflicts of interest.

\section{References}

1. Hyde LK, Cook LJ, Olson LM, Weiss HB, Dean JM. Effect of motor vehicle crashes on adverse fetal outcomes. Obstet Gynecol 2003;102:279-86.

2. Wolf ME, Alexander BH, Rivara FP, Hickok DE, Maier RV, Starzyk PM. A retrospective cohort study of seatbelt use and pregnancy outcome after a motor vehicle crash. J Trauma 1993;34:116-9.

3. Klinich KD, Schneider LW, Moore JL, Pearlman MD. Injuries to pregnant occupants in automotive crashes. Annu Proc Assoc Adv Automot Med 1998;42:57-91.

4. Bunai Y, Nagai A, Nakamura I, Ohya I. Fetal death from abruptio placentae associated with incorrect use of a seatbelt. Am J Forensic Med Pathol 2000;21:207-9.

5. Jamjute P, Eedarapalli P, Jain S. Awareness of correct use of a seatbelt among pregnant women and health professionals: a multicentric survey. J Obstet Gynaecol 2005;25:550-3.

6. Johnson HC, Pring DW. Car seatbelts in pregnancy: the practice and knowledge of pregnant women remain causes for concern. BJOG 2000;107:644-7.

7. Ichikawa M, Nakahara S, Okubo T, Wakai S. Car seatbelt use during pregnancy in Japan: determinants and policy implications. Inj Prev 2003;9:169-72.

8. Taylor AJ, McGwin G Jr, Sharp CE, et al. Seatbelt use during pregnancy: a comparison of women in two prenatal care settings. Matern Child Health J 2005;9:173-9.
9. Weiss H, Sirin H, Levine JA, Sauber E. International survey of seat belt use exemptions. Inj Prev 2006;12:258-61.

10. Transport Department, The Government of the Hong Kong Special Administrative Region. Protect your unborn child in a car. Available from: http://www.td.gov.hk/filemanager/ en/content_174/belt-e.pdf. Accessed Aug 2016.

11. Yu CH, Chan LW, Lam WC, To WK. Pregnant women's knowledge and consumption of long-chain omega-3 polyunsaturated fatty acid supplements. Hong Kong J Gynaecol Obstet Midwifery 2014;14:57-63.

12. Liang KY, Zeger SL. Longitudinal data analysis using generalized linear models. Biometrika 1986;73:13-22.

13. Robertson LS. The validity of self-reported behavioral risk factors: seatbelt and alcohol use. J Trauma 1992;32:58-9.

14. Luley T, Fitzpatrick CB, Grotegut CA, Hocker MB, Myers ER, Brown HL. Perinatal implications of motor vehicle accident trauma during pregnancy: identifying populations at risk. Am J Obstet Gynecol 2013;208:466.e1-5.

15. Grossman NB. Blunt trauma in pregnancy. Am Fam Physician 2004;70:1303-10.

16. Chapter 13: Fortuitous deaths. Why mothers die: report on confidential enquiries into maternal deaths in the United Kingdom 1994-1996. London: Royal College of Obstetrics and Gynaecologists Press; 2001.

17. Cantwell R, Clutton-Brock T, Cooper G, et al. Saving Mothers' Lives: Reviewing maternal deaths to make motherhood safer: 2006-2008. The Eighth Report of the Confidential Enquiries into Maternal Deaths in the United Kingdom. BJOG 2011;118 Suppl 1:1-203.

18. Transport Department, The Government of the Hong Kong Special Administrative Region. Be Smart, buckle up. Available from: http://www.td.gov.hk/filemanager/en/ content_174/seatbelt_leaflet.pdf. Accessed Aug 2016.

19. Transport Department, The Government of the Hong Kong Special Administrative Region. Road Traffic Accident Statistics Year 2013. Available from: http://www.td.gov. hk/en/road_safety/road_traffic_accident_statistics/2013/ index.html. Accessed Aug 2016.

20. Transport Department, The Government of the Hong Kong Special Administrative Region. Seat belt: safe motoring guides. Available from: http://www.td.gov.hk/en/ road_safety/safe_motoring_guides/seat_belt/index.html. Accessed Aug 2016.

21. Transport Department, The Government of the Hong Kong Special Administrative Region. Road Safety Bulletin; March 2001. Available from: http://www.td.gov.hk/ filemanager/en/content_182/rs_bulletin_04.pdf. Accessed Aug 2016.

22. Wallace C. General practitioners knowledge of and attitudes to the use of seat belts in pregnancy. Ir Med J 1997;90:63-4. 